\title{
Pension systems and intragenerational redistribution when labor supply is endogenous
}

\author{
Alessandro Sommacal*
}

March 24, 2004

\begin{abstract}
It is usually thought that a Beveridgean pension system redistributes income more than a Bismarckian one, since it ensures replacement ratios that decrease with income. We check the validity of this result when the fact that pension systems can redistribute also through their effects on labor income is taken into account. Labor market institutions turn out to be crucial. First we study an economy with a competitive labor market: quite surprisingly, inequality is unaffected by a reallocation of funds towards the Beveridgean system. Then we introduce a minimum wage that creates unemployment on the unskilled labor market: in this case the Beveridgean system is proved to reduce inequality.
\end{abstract}

Keywords: Social Security, Intragenerational redistribution, Basic Pension, Beveridgean pension system, Bismarckian pension system

JEL Classification: $\mathrm{H} 55$

*IRES; email:sommacal@ires.ucl.ac.be; the author is very grateful to David de la Croix and Bruno Van der Linden; I wish to thank also Alessandra Casarico for useful suggestions. The usual disclaimer applies. 


\section{Introduction}

Intragenerational redistribution, is one of the main objective of a pension system; for example in the well known proposal of the World Bank (World Bank 1994), the first pillar should exactly perform this task, while the saving or income smoothing function should be achieved by the second and the third pillar.

One of the key elements that determines the degree of intragenerational redistribution is the link between pension payments and social contributions. Two main polar cases can be identified: a basic pension and a Bismarckian pension system. A basic pension (BP), also called a Beveridgean pension, is a flat benefit given to the old without work requirements or means test; it could be seen as a partial basic income conditional on an age requirement ${ }^{1}$. On the other hand a Bismarckian system links pension benefits to wages, i.e. the pension is a certain fraction of the labor income previously earned ${ }^{2}$.

The common way to measure the redistributive effect of a pension system is the relation between the replacement ratio (i.e. the ratio of the pension to the earned income) and the earned income: if the replacement ratio is stable across income groups, the system does not redistribute; if it decreases when

\footnotetext{
${ }^{1}$ The interest towards the introduction of a basic income $(B I)$, that is "an income paid by a political community to all its members on an individual basis, without means test or work requirement" (Van Parijs 2000), is growing in these years. For the analysis of the effects of the $B I$ on economic performance and inequality see for example Rillaers (2000); for the effects of the $B I$ on the unemployment rate see Van der Linden (2002) and (2004). Vanderborght (2002) discusses, from a political science point of view, the possible implementation of the $B I$ in Belgium and Netherlands. The BP is sometimes considered as a first step towards the $B I$.

${ }^{2}$ For the computation of the pension it can be considered either the entire earning history of the individual or only the wages received in the last period of the working age.
} 
income increases, we have a redistributive effect.

In the Beveridgean system the replacement ratio is decreasing; in the Bismarckian system it depends on the specific institutional features but it is in general quite stable. For this reason a Bismarckian system is usually thought to be less redistributive than a Beveridgean one.

Tab. 1 Replacement ratios across income groups in different countries ${ }^{3}$

\begin{tabular}{cccc}
\hline & \multicolumn{3}{c}{ Replacement ratios } \\
\hline France & Half & Average & Twice \\
\hline Germany & 84 & 84 & 73 \\
Italy & 76 & 72 & 75 \\
Japan & $103(1 / 4 \mathrm{x})$ & 90 & $84(3 \mathrm{x})$ \\
United Kingdom & 77 & 56 & 43 \\
United States & 72 & 50 & 35 \\
Canada & 65 & 55 & 32 \\
Netherlands & 76 & 44 & 25 \\
New Zealand & 73 & 43 & 25 \\
\hline
\end{tabular}

Source: Disney and Johnson [2001]

According to this criterion, pension systems can be classified in different groups. Table 1 reports replacement ratios across income groups for different countries; in particular, data concern individuals with the average income, half (for Italy $1 / 4$ ) of the average income and twice (for Italy three times) the average income. On one hand we have Bismarckian countries like France, Germany and Italy, which show relatively stable replacement ratios. On the other hand we have Canada, the Netherlands, and New Zealand which can be classified as Beveridgean and are characterized by replacement ratios that

\footnotetext{
${ }^{3}$ For more data concerning European countries, see Conde-Ruiz and Profeta [2003].
} 
sharply decrease with income. Japan, United Kingdom and United States represent mixed systems, with replacement ratios that decrease but at a slower pace than in Beveridgean countries.

However, it should be remarked that this gives only a partial picture of the effect of pension systems on income inequality. Data based on replacement ratios do not take a key element into account: the $B P$ and the Bismarckian systems create different incentives/disincentives on labor supply (both on the number of hours worked and on the decision to participate to the labor market) and thus affect labor income in different ways. As long as this effect on labor supply is proportionally the same for all income groups, it does not matter in term of redistribution and we do not gain much from the introduction of an endogenous labor supply ${ }^{4}$. However, if the elasticity of labor supply with respect to a change in the benefit formula is different across income groups, pension systems redistribute not simply directly through contributions and pension payments, but also through their effects on labor income .

The implication is that a comparison in terms of redistribution between the $B P$ and the Bismarckian system should take the role of labor supply into account. Empirically this is not an easy task, since it requires for each income group the knowledge of the elasticity of labor supply with respect to a change in the benefit formula; looking at the replacement ratios is for sure more direct. Nevertheless what we want to stress is that, in using simply data on replacement ratios, one should be aware of the simplification implied

\footnotetext{
${ }^{4}$ The literature that studies the redistributive effects of pension systems, usually relies implicitly on this assumption. Indeed the distorsive effect of pension systems on labor supply is simply captured by assuming that a fraction (exogenously determined) of social contributions is wasted. See for example Casarico and Devillanova[2003], Conde-Ruiz and Profeta[2003], Pestieau[1999].
} 
in this methodology; a discussion of the role of labor supply in evaluating the redistributive impact of a pension system and thus of the effect of this simplification is the object of the paper.

To be more precise, we will consider an unfunded pension system composed by two pillars: the first pillar is the $B P$ and the second one is the Bismarckian pension; both pillars are financed with a labor income tax and we assume that at each period the social security budget is balanced. We want to answer the following question: keeping constant the tax rate on labor income, what are the effects of a policy that reallocates funds from the Bismarckian system to the BP? Considering the tax rate on labor income unchanged will allow us to isolate the effect of the different benefit formulas from that of the financing mode.

To analyse the effects of pension systems on labor income, a crucial element is the way in which the labor market is modelled. We consider two different cases. We start by assuming a competitive labor market: labor demand equals labor supply and thus every change in labor supply results in a variation in labor income. Then we take into account the fact that often the labor market, especially for the unskilled, does not clear and thus labor supply is greater than labor demand: as a consequence the unskilled labor income could depend only on labor demand and not on labor supply and thus it would not be affected by a change in the pension system that reduces labor supply. We formalize this idea in a very simple way by introducing a minimum wage in the unskilled labor market.

For a steady state growth path, the main effects of a reallocation of funds from the Bismarckian to the Beveridgean system can be summarized as follows. We have no general equilibrium effects, in the sense that the interest rate and the wage are unaffected; this is due to the fact that labor supply 
and capital reduce in the same proportion. As a consequence output drops. For what concerns inequality, the crucial element is that, assuming the same preference for all individuals, the low skilled reduce their labor supply more than the high skilled. In the case of perfect competition in both the skilled and unskilled sectors, the final effect turns out to be such that the life cycle income is reduced by the same proportion for both the skilled and the unskilled workers: thus, in contrast with the standard results that are simply based on replacement ratios across income groups, income inequality is unaffected. Things are different if we introduce a minimum wage in the unskilled labor market: in this case the life cycle income of the skilled still decreases, but the life cycle income of the unskilled increases: thus inequality is reduced. Finally we assess also the effect on individual utility. In the case of perfect competition in both the skilled and unskilled sectors, the utility of the skilled reduces while the effect on the utility of the unskilled is theoretically ambiguous: though their income always decreases, their leisure could increase even more compensating in terms of utility the drop in consumption levels. In the case of a minimum wage in the unskilled labor market, we show that the utility of the unskilled for sure increases, since their life cycle income is increased and their leisure is unchanged; the effect on the utility of the skilled is ambiguous.

The paper is organized in five sections. Section 2 presents the general features of the model. In Section 3, we consider the competitive equilibrium and in Section 4, we study the economy with a minimum wage in the unskilled labor market. Section 5 concludes. Appendix A and B contain some proofs. 


\section{The model}

We use an OLG model in which there is a continuum of consumers divided in two groups: the skilled ( group 1) and the unskilled (group 2) workers. Population is assumed to be constant and thus it is normalized to one. Moreover we assume that the number of the skilled is equal to $e$, while the number of the unskilled is equal to $1-e^{5}$.

Agents live for two periods and have perfect foresight. In the first period they supply $l_{i t}$ units of labor and receive a wage $w_{i t}$, where the index $i$ refers to the skill $(i \in 1,2)$; labor income is used to pay social contributions and finance current consumption and savings. In the second period, they are retired and finance their consumption using savings and the pension paid by the government.

We here examine in detail the behavior of the government, the consumers and the firms. Then we derive in sections 3 and 4 the equilibrium conditions for the competitive economy and for the economy with a minimum wage in the unskilled labor market.

In what follows we carefully make a distinction between labor supply (that is denoted without any accent), labor demand (that is denoted by a tilde) and labor effectively exchanged in the market (that is denoted by a hat).

\footnotetext{
${ }^{5}$ In what follows we do not endogenize the choice to invest in human capital and we focus on the role of labor supply; Docquier and Paddison (2003) study the effects of different pension systems on the decision to invest in human capital.
} 


\section{$2.1 \quad$ Firms}

We consider a representative firm that uses both skilled and unskilled labor. The production function is Cobb-Douglas:

$$
Y_{t}=K_{t}^{\alpha}\left(\tilde{L}_{1 t}+\sigma \tilde{L}_{2 t}\right)^{1-\alpha}
$$

where $0<\sigma<1$ is the exogenous relative productivity of the unskilled.

Profit maximization implies that, given the wage of the skilled $w_{1 t}$, the wage of the unskilled $w_{2 t}$, and the interest rate $R_{t}{ }^{6}$, capital demand and labor demands are, for an interior solution (i.e. for positive demands for both skilled and unskilled workers), such that:

$$
\begin{gathered}
R_{t}=\alpha \tilde{k}_{t}^{\alpha-1} \\
w_{1 t}=(1-\alpha) \tilde{k}_{t}^{\alpha} \\
w_{2 t}=\sigma(1-\alpha) \tilde{k}_{t}^{\alpha}
\end{gathered}
$$

where $\tilde{k}=\frac{K_{t}}{\tilde{L}_{t}}$.

To have an interior solution, the ratio between the wages has to be equal to $\sigma$, that is:

$$
w_{2 t}=\sigma w_{1 t}
$$

If $w_{2 t}>\sigma w_{1 t}$ the demand for the unskilled is zero and thus only equation (3) and (2) hold; if $w_{2 t}<\sigma w_{1 t}$ the demand for the skilled is zero and thus only equation (4) and (2) hold.

\subsection{Government}

The government pays to each old age individual a pension:

$$
P_{i t+1}=b_{t+1} w_{i t} \hat{l}_{i t}+p_{t+1}
$$

\footnotetext{
${ }^{6} \mathrm{We}$ assume full depreciation and thus the user cost of capital is equal to the interest rate.
} 
where the second term of the right hand side is the $B P$ (thus it is independent of labor income and the same across individuals of the same generation) and the first is the Bismarckian pension (which is a fraction $b_{t+1}$ of the gross labor income previously earned). On each young worker is levied a labor tax equal to:

$$
T_{i t+1}=\tau_{t+1} w_{i t+1} \hat{l}_{i t+1}
$$

We assume that the budget is balanced and thus we have:

$e b_{t+1} w_{1 t} \hat{l}_{1 t}+(1-e) b_{t+1} w_{2 t} \hat{l}_{2 t}+p_{t+1}=e \tau_{t+1} w_{1 t+1} \hat{l}_{1 t+1}+(1-e) \tau_{t+1} w_{2 t+1} \hat{l}_{2 t+1}$

Thus if we define aggregate labor exchanged as:

$$
\hat{L}_{t}=e \hat{l}_{1 t}+(1-e) \sigma \hat{l}_{2 t}
$$

and we take (5) into account, the budget constraint of the government can be written as:

$$
b_{t+1} w_{1 t} \hat{L}_{t}+p_{t+1}=\tau_{t+1} w_{1 t+1} \hat{L}_{t+1}
$$

We consider the case in which the sequences of the tax rate $\left\{\tau_{t}\right\}_{t=0}^{\infty}$ and of the $B P\left\{p_{t}\right\}_{t=0}^{\infty}$ are exogenously given, while the sequence $\left\{b_{t}\right\}_{t=0}^{\infty}$ of the Bismarckian pension parameter is endogenously determined according to equation (10), in order to ensure that the government budget is balanced. Moreover we assume that the tax rate is constant, that is $\tau_{t+1}=\tau_{t}=\tau$ for every t. Thus equation (10) becomes:

$$
b_{t+1}=\frac{\tau w_{1 t+1} \hat{L}_{t+1}-p_{t+1}}{w_{1 t} \hat{L}_{t}}
$$

Finally we also assume that

$$
\frac{p_{t+1}}{w_{1 t} \hat{L}_{t}}=\gamma
$$

Equation (12) simply means that the ratio between the $B P$ and the aggregate labor income of the previous period is kept unchanged over time, in such a 
way that the "generational" replacement ratio assured by the $B P$ is the same in each period. Substituting (12) into (11) we get:

$$
b_{t+1}=\frac{\tau w_{1 t+1} \hat{L}_{t+1}}{w_{1 t} \hat{L}_{t}}-\gamma
$$

\subsection{Consumers}

To keep things tractable, we take a convenient and quite standard specification for the utility function: we assume it is logarithmic in consumption and linear in labor. Thus consumers solve the following optimization problem:

$$
\begin{gathered}
\max \log c_{i t}+\beta \log d_{i t+1}-\left(1-l_{i t}\right) \\
\text { s.t. } \\
c_{i t}=(1-\tau) w_{i t} l_{i t}-s_{i t} \\
d_{i t+1}=R_{t+1} s_{i t}+b_{t+1} w_{i t} l_{i t}+p_{t+1}
\end{gathered}
$$

In the way we have written the optimization program, it is implicit that consumers know the formula according to which the pension is computed, but does not take into account the fact that $b_{t+1}$ and $p_{t+1}$ also depend from their own choices according to equations (13) and (12). The solutions to this optimization problem are:

$$
\begin{gathered}
s_{i t}=\frac{\left[R_{t+1} \beta(1-\tau)-b_{t+1}\right]}{R_{t+1}(1+\beta)} w_{i t} l_{i t}-\frac{p_{t+1}}{R_{t+1}(1+\beta)} \\
l_{i t}=(1+\beta)-\frac{p_{t+1}}{\left[R_{t+1}(1-\tau)+b_{t+1}\right] w_{i t}}
\end{gathered}
$$

From equation (17) we can see that savings are determined by two components : since the logarithmic utility function is homothetic, the first term is as usual a fraction of labor income, which in this case has to be determined since labor supply is endogenous; the second term depends on the BP. Moreover notice that the propensity to save out of labor income, i.e. $s_{i t} / w_{i t} l_{i t}$, 
is higher for the skilled than for the unskilled; this is due to the fact that, for high skilled workers non labor income represented by the $B P$ is relatively less important.

From equation (18) we can see that in absence of the $B P$ labor supply is independent of the wage, because the substitution effect is exactly offset by the income effect: this is a standard feature with the assumed utility function. Introducing non labor income, like the $B P$, alters the equilibrium between these two effects and as a consequence labor supply depends positively on $w_{i t}$.

\section{Competitive equilibrium}

If we substitute (12) into (18) we get:

$$
l_{i t}=(1+\beta)-\frac{\gamma w_{1 t} \hat{L}_{t}}{\left[R_{t+1}(1-\tau)+b_{t+1}\right] w_{i t}}
$$

Aggregate labor supply is:

$$
L_{t}=e l_{1 t}+(1-e) \sigma l_{2 t}
$$

and thus substituting (19) into (20) we obtain:

$$
L_{t}=(1+\beta)(e+(1-e) \sigma)-\gamma \frac{\hat{L}_{t}}{\left[R_{t+1}(1-\tau)+b_{t+1}\right]}
$$

We assume that labor demand equals labor supply in both markets, and thus: $l_{i t}=\tilde{l}_{i t}=\hat{l}_{i t}$ and $L_{i t}=\tilde{L}_{i t}=\hat{L}_{i t}$. As a consequence equation (21) becomes:

$$
L_{t}=(1+\beta) \bar{h} \frac{\left[R_{t+1}(1-\tau)+b_{t+1}\right]}{\left[R_{t+1}(1-\tau)+b_{t+1}+\gamma\right]}
$$

where $\bar{h}=(e+(1-e) \sigma)$ is the average productivity. Substituting equation (22) into equation (19), we have the individual labor supply:

$$
l_{i t}=(1+\beta)-\gamma \frac{\bar{h}}{h_{i}} \frac{(1+\beta)}{\left[R_{t+1}(1-\tau)+b_{t+1}+\gamma\right]}
$$


where $h_{i}$ is the productivity of agent $i$, that is $h_{1}=1$ and $h_{2}=\sigma$.

We now consider the rule of accumulation of capital:

$$
K_{t+1}=S_{t}
$$

that simply states that the aggregate capital at time $t+1$ is build up on aggregate savings of the previous period. From equations (12) and (17), aggregate savings are given by:

$$
S_{t}=\frac{R_{t+1} \beta(1-\tau)-b_{t+1}-\gamma}{R_{t+1}(1+\beta)} w_{1 t} L_{t}
$$

and thus equation (24) can be written as:

$$
k_{t+1} L_{t+1}=\frac{R_{t+1} \beta(1-\tau)-b_{t+1}-\gamma}{R_{t+1}(1+\beta)} w_{1 t} L_{t}
$$

Substituting equations (2), (3) and (22) into equations (26) and (13) we get a system in $b_{t+1}$ and $k_{t+1}$. Once $k_{t+1}$ is determined, $R_{t+1}, w_{1 t}$ and $w_{2 t}$ are also determined. Then, knowing $b_{t+1}, w_{1 t}$ and $R_{t+1}$, we can determine labor supplies, savings and consumption levels.

In the next subsection we solve the model for the case of a long run equilibrium, i.e. a steady state.

\subsection{Steady state}

In steady state, equation (13) is:

$$
b=\tau-\gamma
$$

Using equations (2), (3) and (27), equation (26) becomes:

$$
k=\frac{\left[\alpha k^{\alpha-1} \beta(1-\tau)-\tau\right]}{\alpha k^{\alpha-1}(1+\beta)}(1-\alpha) k^{\alpha}
$$


This equation implicitly defines the steady state level of $k$ and can be solved to find:

$$
k_{s s}=\left[\frac{\alpha(1-\alpha) \beta(1-\tau)}{\alpha(1+\beta)+(1-\alpha) \tau}\right]^{\frac{1}{1-\alpha}}
$$

For our purpose it's important to notice that, since (29) does not depend on $\gamma$, the policy we are studying does not affect the ratio between capital and aggregate labor; this means that $K$ and $L$ change in the same direction and in the same proportion. As an implication, we have also that, according to equations (2), (3) and (4), $R, w_{1}$ and $w_{2}$ remain unaffected and thus, a reallocation of funds between the $B P$ and the Bismarckian system has no general equilibrium effects, for a given value of the social contribution rate $\tau$ 7.

Substituting equation (27) into equation (22), we can write aggregate labor supply in steady state as:

$$
L=\frac{[R(1-\tau)+(\tau-\gamma)]}{[R(1-\tau)+\tau]}(1+\beta) \bar{h}
$$

In the same way, we get individual labor supply:

$$
l_{i}=(1+\beta)-\frac{(1+\beta)}{[R(1-\tau)+\tau]} \frac{\bar{h}}{h_{i}} \gamma
$$

first period consumption:

$$
c_{i}=[R(1-\tau)+\tau-\gamma] \frac{w}{R} h_{i}
$$

and second period consumption:

$$
d_{i}=\beta[R(1-\tau)+\tau-\gamma] w h_{i}
$$

\footnotetext{
${ }^{7}$ It can be shown that this result is still valid, as long as the utility function is a CES in consumption (no matter which specification for the utility of leisure is assumed). The assumption that turns out to be crucial, concerns the specific policy rule we have assumed in equation (12), i.e. the assumption of a constant generational replacement ratio.
} 


\subsection{The steady state effects of a reallocation of funds from the Bismarckian system to the Basic Pension}

We are now ready to analyse the effects of an increase in $\gamma$. We can immediately notice from (30) and (31) that both aggregate and individual labor supply decrease. If we recall that, from equation (29), $K$ change in the same direction and proportion to $L$, we obtain that also the aggregate capital stock is reduced; as a consequence both aggregate output and per capita output drop. Thus we can conclude that the effects on economic performance are negative.

It is important to analyse also the effects on individual variables. If we take the derivative of individual labor supply (31) with respect to $\gamma$ :

$$
\frac{\partial l_{i}}{\partial \gamma}=-\frac{(1+\beta)}{[R(1-\tau)+\tau]} \frac{\bar{h}}{h_{i}}
$$

we see that it is decreasing in absolute value in $h_{i}$; thus the unskilled reduce their work hours more than the skilled. The same is true also for the elasticity of labor supply with respect to $\gamma$ :

$$
\frac{\partial l_{i}}{\partial \gamma} \frac{\gamma}{l_{i}}=-\frac{1}{[R(1-\tau)+\tau] h_{i}-\gamma \bar{h}} \bar{h} \gamma
$$

The analysis of inequality is less straightforward. We define the individual life cycle income as:

$$
y_{i} \equiv(1-\tau) w_{1} h_{i} l_{i}+\frac{b w_{1} h_{i} l_{i}}{R}+\frac{p}{R}
$$

Considering that $b=\tau-\gamma$ from (27) and $p=\gamma w_{1} \hat{L}$ from (12) and using aggregate and individual labor supply (30) and (31), $y_{i}$ becomes:

$$
y_{i}=[R(1-\tau)+\tau-\gamma](1+\beta) \frac{w_{1}}{R} h_{i}
$$

From this equation we can easily get:

$$
\frac{\partial y_{i}}{\partial \gamma}=-(1+\beta) \frac{w_{1}}{R} h_{i}
$$


Thus, though the high skilled reduce their labor supply more than the unskilled, the opposite is true for individual income; this is due to the fact that the wage $w_{1} h_{i}$ paid for one hour of work is higher for individual with high productivity. But what really matters is the consequent effect on the reduction of income in percentage term; using equations (38) and (37) we have:

$$
\frac{\partial y_{i}}{\partial \gamma} \frac{1}{y_{i}}=-\frac{1}{[R(1-\tau)+\tau-\gamma]}
$$

According to equation (39), the income of all households turns out to be reduced in the same proportion, independently of their productivity endowment $h_{i}$. Thus if we measure inequality by an index that abstracts from scale effects ${ }^{8}$, we obtain, quite surprisingly, that inequality is unaffected by a reallocation of funds from the Bismarckian system to the $B P$.

Finally we can also assess the effect on individual utility. We have:

$$
\frac{\partial U_{i}}{\partial \gamma}=\frac{1}{c_{i}} \frac{\partial c_{i}}{\partial \gamma}+\beta \frac{1}{d_{i}} \frac{\partial d_{i}}{\partial \gamma}-\frac{\partial l_{i}}{\partial \gamma}
$$

which , using (32) and (33), can be written as:

$$
\frac{\partial U_{i}}{\partial \gamma}=-(1+\beta)\left[\frac{1}{R(1-\tau)+\tau-\gamma}-\frac{1}{R(1-\tau)+\tau} \frac{\bar{h}}{h_{i}}\right]
$$

Thus, the utility of the skilled decrease for sure, since in this case $h_{i}=1$. Utility of the unskilled could increase if their level of productivity $h_{i}=\sigma$ was sufficiently low : this is due to the fact that, though their income and their consumption levels always decrease, their leisure could increase even more, compensating the drop in $c_{2}$ and $d_{2}$.

\footnotetext{
${ }^{8} \mathrm{An}$ inequality index is said to abstract from scale effects exactly when it is invariant to a proportional change of all income. Most of the main indexes used, such as the Gini, the Atkinson, and the Theil ones, satisfy this property. See Myles (1995) and the references quoted therein.
} 


\subsection{Dynamics}

In Section 3.2 we have analysed the long run effects of a change in parameter $\gamma$; in this section we study the transition dynamics. In particular we ask if the absence of general equilibrium effects of an increase in $\gamma$, is still valid during the adjustment to the steady state. The answer turns out to be negative. Moreover, we study the effect on individual utilities for each generation: we show that a reallocation of funds towards the $B P$ causes the unskilled to be gainers and the skilled to be losers. This holds true for each generation.

For these purposes, we calibrate the model and we simulate it using Dynare (see Juillard (1996)). The Blanchard-Kahn condition is satisfied since there are five eigenvalues larger than one in modulus for five forwardlooking variables. For the calibration of the model, the length of a generation is assumed to be 30 years. The key parameters we have to calibrate are: $\alpha$ (the share of capital in the production function), $A$ (the scaling factor of the production function), $\beta$ (the rate of time preferences), $\sigma$ (the productivity of the unskilled), $\tau$ (the social contribution rate). We assume standard values for $\alpha$ and $\beta$ : $\alpha=0.3$ and $\beta=0.3$ (which implies a quarterly discount factor of 0,99$)$. $A$ is simply a scale parameter that is usually introduced in the production function (that becomes $Y=A K^{\alpha} L^{1-\alpha}$ ) and we set it equal to 9.5. For the value of $\sigma$, we choose 0.4 in order to have a wage dispersion characterized by the ratio highest to lowest wage $\left(\frac{w_{1}}{w_{2}}=\frac{1}{\sigma}\right)$ equal to 2.5 , that is consistent with the evidence reported by Rillaers (2000). Finally the value of $\tau$ is set equal to 0.15, as in Docquier and Paddison (2003). These parameters imply a steady state annual interest rate of $4 \%$.

We study the effect of a change in $\gamma$ from a value of 0,04 to a value of $0.09 .^{9}$

\footnotetext{
${ }^{9}$ The results are qualitatively the same if we consider different initial and final values
} 
First of all we consider the aggregate variables. Figures 1-6 show the dynamic behavior of: the interest rate $(R)$, the wage of the skilled $\left(w_{1}\right)$, the ratio between aggregate capital and labor $(k)$, the aggregate labor $(L)$, the aggregate capital $(K)$, the aggregate saving $(S)$.

In particular, from Figure 1 and 2 we can see that, although the steady values of $R$ and $w_{1}$ remain unchanged, during the transition general equilibrium effects take place: initially $R$ decreases and $w_{1}$ increases, but, starting from the second period, they respectively grow and drop so to achieve in the fifth period their previous values. These paths are determined by the dynamics of $k$ showed in Figure 3. The behavior of $k$ can be understood by looking at the response of $L, K$ and $S$ in Figures 4-6. In particular, the initial increase in $k$ is due to the nature of the variable $K: K$ is predetermined at the time in which the change in $\gamma$ takes place, because it is build up on savings of the previous period. Thus $K$ starts decreasing only after one period, while $L$ and $S$ immediately drop. In other words, a reallocation of funds towards the $B P$ has a negative effect on labor supply, while physical capital is initially fixed; this raises the marginal productivity of labor and decreases the marginal productivity of capital, causing the wage and the interest rate respectively to grow and to drop. The wages and the interest rate revert to their initial level once capital adjusts to the new steady state.

Figure 7 and 8 show the utility respectively of skilled and of unskilled workers. For the skilled, the effect turns out to be negative for all generations: a reallocation of funds towards the $B P$ causes the utility of these households to drop until the new steady state is achieved. The opposite is true for the unskilled, who, independently of the generation to which they belong, gain for $\gamma$ (for example the initial value of $\gamma$ could be set equal to 0 , if we want to study the effects of an introduction of the $B P$ ). 
from an increase in $\gamma \cdot{ }^{10}$

\footnotetext{
${ }^{10}$ Notice that the path of the utility of the unskilled is not monotonic (the maximum of utility is reached after one period); however the utility is always above the level of the old steady state.
} 

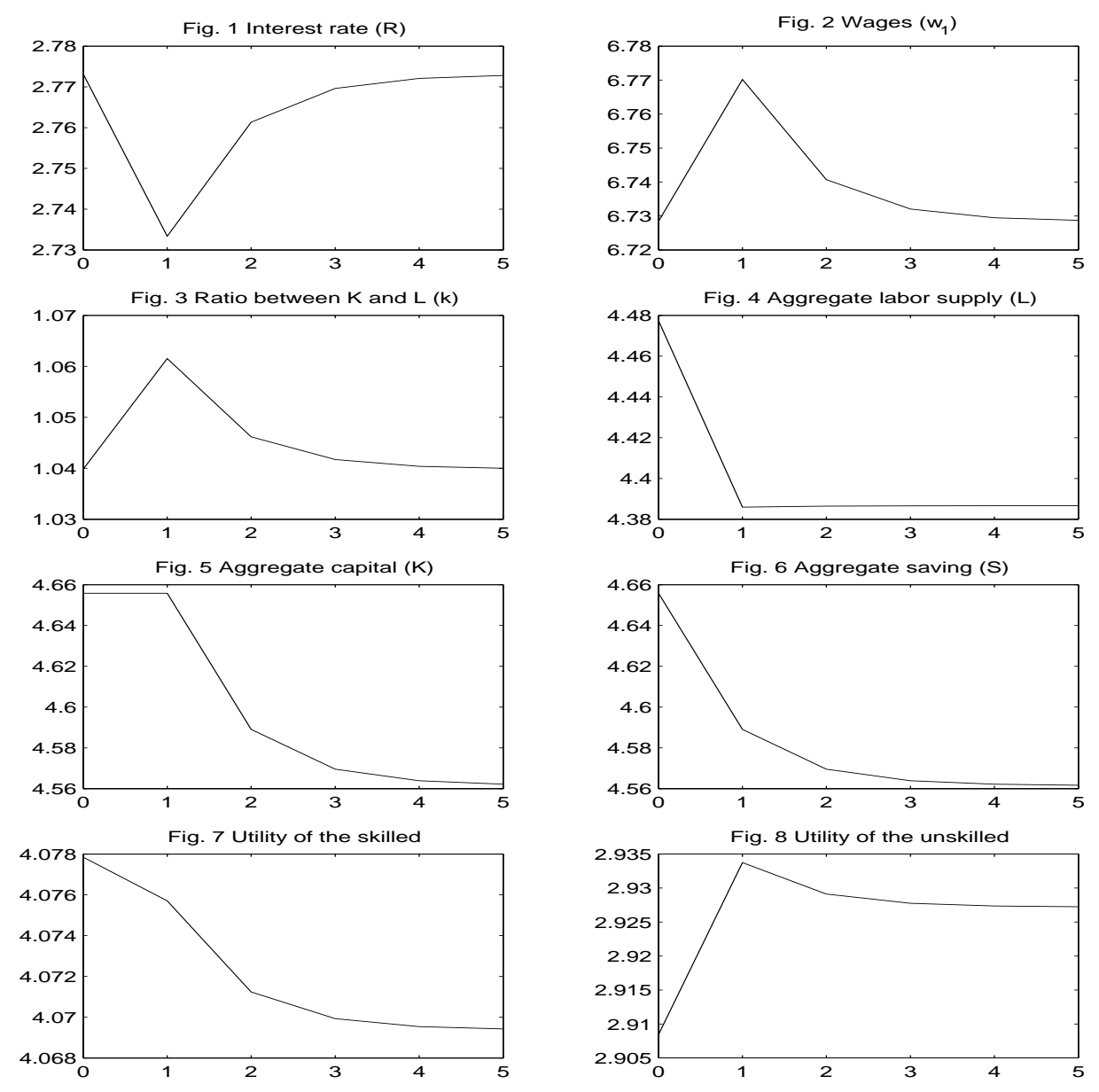

Figure 1: Dynamics 


\section{Equilibrium with a minimum wage}

In the previous section we have assumed that $w_{1 t}$ and $w_{2 t}$ change in order to clear both the skilled and the unskilled labor market. In this section we continue to assume that the wage of the skilled $w_{1 t}$ moves freely, but we introduce a minimum wage $\bar{w}_{2 t}$ in the unskilled labor market, that is:

$$
w_{2 t} \geq \bar{w}_{2 t}
$$

In particular, as in Cahuc and Michel (1996), we fix:

$$
\bar{w}_{2 t}=\bar{w}_{2}>w_{2}^{*}
$$

where $w_{2}^{*}$ is the steady state competitive wage, i.e. $w_{2}^{*}=\sigma(1-\alpha) k_{s s}^{\alpha}$ with $k_{s s}$ given by equation (29); in other terms the minimum wage is constant over time and higher than the steady state competitive wage.

As a consequence notice that aggregate labor exchanged is ${ }^{11}$ :

$$
\hat{L}_{t}=e \hat{l}_{1 t}+(1-e) \sigma \hat{l}_{2 t}=e l_{1 t}+(1-e) \sigma \tilde{l}_{2 t}
$$

Indeed $w_{1 t}$ moves freely to clear the skilled labor market and thus $l_{1 t}=$ $\tilde{l}_{1 t}=\hat{l}_{2 t}$, while due to the presence of the minimum wage we have that $l_{2 t} \geq \tilde{l}_{2 t}=\hat{l}_{2 t}$ (where the equality holds only when the minimum wage is not binding).

The dynamics turns out to be characterized by three different regimes. Depending on initial conditions we can start in any of these regimes; however, as we will show, the dynamics is such that the economy ends up in the third regime.

\footnotetext{
${ }^{11}$ For the notation we use see section 2
} 
First Regime: both skilled and unskilled workers are fully employed $\left(\sigma w_{1 t}=w_{2 t}>\bar{w}_{2}, l_{1 t}=\tilde{l}_{1 t}=\hat{l}_{2 t}\right.$ and $\left.l_{2 t}=\tilde{l}_{2 t}=\hat{l}_{2 t}\right)$

If $\sigma w_{1 t}=w_{2 t}>\bar{w}_{2}$ is an equilibrium, i.e. the minimum wage is not binding, both the skilled and the unskilled are fully employed. The dynamics is the one of the competitive economy of section 3 : thus $k_{t}$ has to converge to $k_{s s}$ and starts decreasing. As consequence also wages decrease; at a certain point in time $\bar{t}, \bar{w}_{2}$ is reached and the minimum wage becomes binding.

After time $\bar{t}$, wages should decrease to make aggregate labor demand equal to aggregate labor supply; but this is not possible for the wage of the unskilled due to the minimum wage. Notice that, since skilled and unskilled workers are perfect substitutes due to equation (1), only aggregate labor demand matters for the firm. Thus in a situation in which aggregate labor demand is below aggregate labor supply, the composition of labor demand between skilled and unskilled workers is not determined. If we assume that the firm employs first of all the unskilled, then the wage of the skilled immediately decreases to clear the market and we jump directly to the third regime. If we assume that the firm employs first of all the skilled, then we enter in the second regime, that, as we will see, finally ends up in any case in the third regime.

Second Regime: skilled workers are fully employed and we have partial involuntary unemployment among the unskilled ( $\sigma w_{1 t}=$ $w_{2 t}=\bar{w}_{2}, l_{1 t}=\tilde{l}_{1 t}=\hat{l}_{2 t}$ and $l_{2 t}>\tilde{l}_{2 t}=\hat{l}_{2 t}>0$ )

At $\hat{t}+1$, aggregate labor demand is below aggregate labor supply. If we assume that the firm hires first of all the skilled, we have that the skilled are all employed, while in the labor market of the unskilled we have some 
involuntary unemployment. Since the labor market of skilled workers clears, $w_{1 t}$ does not change and we still have $\sigma w_{1 t}=w_{2 t}=\bar{w}_{2}$.

Due to the fact that the minimum wage $\bar{w}_{2}$ is constant, the same is true also for $w_{1 t}, k_{t}$ and $R_{t+1}$; i.e. $w_{1 t}=\bar{w}_{1}, k_{t}=\bar{k}, R_{t+1}=\bar{R}$. Thus using equation (13) and the rule of accumulation of capital (24), the dynamics of the economy is in this case described by the following system:

$$
\left\{\begin{array}{l}
b_{t+1}=\tau \frac{\bar{w}_{1} \hat{L}_{t+1}}{\bar{w}_{1} \hat{L}_{t}}-\gamma=\tau \frac{\hat{L}_{t+1}}{\hat{L}_{t}}-\gamma \\
\bar{k} \hat{L}_{t+1}=\frac{\bar{R} \beta(1-\tau)-b_{t+1}-\gamma}{R(1+\beta)} \bar{w}_{1} \hat{L}_{t}
\end{array}\right.
$$

Substituting the first equation into the second one, we get:

$$
\hat{L}_{t+1}=\theta \hat{L}_{t}
$$

or, in terms of capital stock:

$$
K_{t+1}=\theta K_{t}
$$

where:

$$
\theta=\frac{\beta(1-\tau) \bar{w}_{1} \bar{R}}{(1+\beta) \bar{k} \bar{R}+\tau \bar{w}_{1}}=\frac{\alpha(1-\alpha) \beta(1-\tau)}{\alpha(1+\beta)+(1-\alpha) \tau} \bar{k}^{\alpha-1}
$$

According to equation (45), the sign of $\theta$ is crucial in determining the behavior of $\hat{L}_{t}$. Notice that from equation (42) we have:

$$
\sigma(1-\alpha) \bar{k}^{\alpha}>\sigma(1-\alpha) k_{s s}^{\alpha}
$$

i.e.:

$$
\bar{k}>k_{s s}
$$

from which, using equation (29), follows:

$$
\bar{k}>\left[\frac{\alpha(1-\alpha) \beta(1-\tau)}{\alpha(1+\beta)+(1-\alpha) \tau}\right]^{\frac{1}{1-\alpha}}
$$

Equation (50) implies that $\theta<1$ and thus the sequence $\hat{L}_{t}$ is decreasing. 
Third Regime: skilled workers are fully employed and we have full involuntary unemployment among the unskilled $\left(\sigma w_{1 t}<w_{2 t}=\right.$ $\bar{w}_{2}, l_{1 t}=\tilde{l}_{1 t}=\hat{l}_{2 t}$ and $l_{2 t}>\tilde{l}_{2 t}=\hat{l}_{2 t}=0$ )

However, the sequence $\hat{L}_{t}$ is bounded below by labor supply of skilled workers, because $w_{1}$ can change freely: when $\hat{L}_{t}$ starts becoming lower than $e l_{1 t}, w_{1}$ decrease and we no longer have $\sigma w_{1 t}=w_{2 t}=\bar{w}_{2}$. From then onwards, labor demand for the unskilled $\tilde{l}_{2}$ is equal to zero. The economy is not described by the system (44), but it simply resembles the dynamics of a competitive economy like the one described in section 3, with the difference that now we have only skilled workers. Thus it converges to a steady steady, on which we focus in the next subsections.

The result that in the long run all the unskilled are unemployed could seem quite strange; however, if we consider that in the "two types" model we are using the unskilled are simply the individuals at the bottom of the distribution of abilities, it turns out to be more reasonable ${ }^{12}$.

\subsection{Steady state}

As we have shown above, the economy finally ends up in the third regime and converges to a steady state. In steady state, the ratio between aggregate stock of capital and aggregate labor is still given by equation (29) and thus it is the same of an economy without a minimum wage. However, aggregate stock of capital and aggregate quantity of labor have for sure different values

\footnotetext{
${ }^{12}$ This result depends on the assumption of a constant minimum wage over time; Cahuc and Michel (1996) consider also a different case. We do not pursue this point here since our purpose is not to study the implication of different minimum wage policies, but to introduce in a simple way some form of unemployment and study its implication for the redistributive role of pension systems.
} 
with respect to section 3. In particular, as we have said before, the demand for the unskilled $\tilde{l}_{2}$ is equal to zero, and the aggregate labor demand is equal to the aggregate labor supply of the skilled, i.e.:

$$
L=\tilde{L}=e l_{1}
$$

Thus using equations (12),(13), (18) and (51) we get the expression for labor supply of the skilled ${ }^{13}$ :

$$
l_{1}=(1+\beta) \frac{[R(1-\tau)+\tau-\gamma]}{[R(1-\tau)+\tau-\gamma(1-e)]}
$$

\subsection{The steady state effects of a reallocation of funds from the Bismarckian system to the Basic Pension}

As in the case of a competitive economy we have that, when $\gamma$ increase, $k$, $R$ and $w_{1}$ do not change, i.e. we have no general equilibrium effects.

Labor supply of the skilled decreases, since using equation (52) we obtain:

$$
\frac{\partial l_{1}}{\partial \gamma}=-(1+\beta) e \frac{R(1-\tau)+\tau}{[R(1-\tau)+\tau-\gamma(1-e)]^{2}}
$$

that is negative. As a consequence, since $k=\frac{K}{e l_{1}}$ does not change when $\gamma$ increase, we have that $K$ has to decrease; thus also aggregate and per capita output drop.

We now study the effect of a reallocation of funds toward the $B P$ on life cycle income inequality. The income of the skilled is the same as the case of a competitive economy and decreases as $\gamma$ increase. The income of the unskilled it's simply equal to the discounted value of $B P$ :

$$
y_{2}=\frac{p}{R}=\frac{\gamma w_{1} e l_{1}}{R}
$$

\footnotetext{
${ }^{13}$ We focus on labor supply of the skilled, since labor supply of the unskilled is not relevant in determining the effects on income inequality, due to the fact that the demand of unskilled labor is equal to zero in steady state.
} 
It can be shown (see Appendix A) that the derivative of the $B P$ with respect to $\gamma$ is positive and thus the income of the unskilled increases (Notice that this is not trivial since $\gamma$ on one hand as a positive effect on $p$ and on the other hand has a negative impact on it since it reduces $l_{1}$ ).

Since income of the skilled decreases while income of the unskilled increases, income inequality is reduced.

Finally we compute the effect on individual utilities.

It can be shown (see Appendix B) that the effect on the utility of the skilled is in general ambiguous; in fact:

$$
\frac{\partial U_{1}}{\partial \gamma}=-(1+\beta)\left\{\frac{[R(1-\tau)+\tau-\gamma(1-e)]^{2}-e[R(1-\tau)+\tau][R(1-\tau)+\tau-\gamma]}{[R(1-\tau)+\tau-\gamma][R(1-\tau)+\tau-\gamma(1-e)]^{2}}\right\}
$$

has an ambiguous sign. However for $\gamma$ that tend to zero, i.e. if we are considering the introduction of a $B P$, the utility of the skilled for sure decreases.

The utility of the unskilled increases for sure, since income and thus consumption levels increase and leisure is unchanged.

\section{Conclusions}

The aim of this work is to study the effects of a basic pension, whose distinctive feature is the independence on work requirements. To capture this specificity and isolate the effect of different benefit formulas from that of the financing mode, we study a policy that reallocates funds from a Bismarckian pension scheme to a basic pension, keeping social contributions unchanged. We model this policy assuming that the basic pension is linked to the aggregate labor income of the previous period to have a constant 'generational' replacement ratio. To keep the analysis tractable, we make some simplifying assumptions. In particular we use specific functional forms for the utility 
and the production functions.

The result concerning the effects on economic performance is robust to different assumptions for the utility function, as long as labor supply is upward sloping (i.e. the substitution effect prevails on the income effect). The absence of effects on inequality in the competitive economy, for sure depends crucially on the functional form that we have used. However, the main message, i.e. the fact that the redistribution of a pension system could be reduced by effects passing through labor supply, is still valid as long as we consider utility functions for which the elasticity of labor supply to the reallocation of funds is higher for the unskilled than for the skilled.

Through the paper we assume perfect substitution between skilled and unskilled workers and a useful extension is the introduction of a certain degree of complementarity between the two types of labor.

Further research will be important to a have a more general picture of the role that labor supply and labor market institutions could play in determining the shape and the size of the effects of pension systems on income inequality. Our purpose in this paper is to draw the attention on this issue and to start exploring it.

We show that in the long run a reallocation of funds towards the basic pension has no general equilibrium effects, since the interest rate and the wage are unaffected. Moreover it has a negative impact on economic performance, since labor supply, capital and output drop.

The working of the labor market is crucial for the effect on income inequality; we distinguish two different cases: in the first one all markets are competitive, while in the second one there is a minimum wage in the unskilled labor market. In the competitive economy case, a reallocation of funds towards the basic pension does not affect income inequality, since life cycle 
incomes of the skilled and of the unskilled decrease in the same proportion. In the economy with a minimum wage, the effect of this policy is to decrease the life cycle income of the skilled, while increasing the life cycle income of the unskilled: as a consequence income inequality is reduced. The explanation of the different results we get in these two cases, relies on the fact that in the presence of a minimum wage we have an excess of supply of unskilled labor and thus only labor demand matter in determining the quantity of unskilled labor that is effectively exchanged in the market; as a consequence a reduction in the labor supply of the unskilled does not affect their life cycle income. One implication of our results is that, when measuring the effects of pension systems on inequality, looking simply at the replacement ratios across income groups could be a partial procedure; one should be aware of the role that labor supply and labor market institutions could play. 


\section{References}

- Breyer F. and Straub M. [1993]. 'Welfare Effects of Unfunded Pension Systems when Labor Supply is Endogenous', Journal of Public Economics, 50, 77-91.

- Cahuc P. and Michel P. [1996]. 'Minimum wage unemployment and growth', European Economic Review, 40, 1463-1482.

- Casarico A. and Devillanova C. [2003]. 'Capital-skill Complementarity and the Redistributive Effects of Social Security Reform', CEPR Discussion Paper n3773.

- Conde-Ruiz J.I. and Profeta P. [2003]. 'What Social Security: Beveridgean or Bismarkian?', Fedea Documento de Trabajo 2003-16.

- de la Croix D. and Michel P. [2002]. A Theory of Economic Growth: Dynamics and Policy in Overlapping Generations, Cambridge University Press.

- Disney R. and Johnson P. ed. [2001]. 'Pension Systems and Retirement Incomes across OECD Countries', Edward Elgar editor.

- Docquier F. and Paddison O. [2003]. 'Growth and Equality Effects of Pension Plans', Journal of Macroeconomics, 25, 47-71.

- Juillard M. [1996]. 'A Program for the Resolution and Simulation of Dynamic Models with Forward Variables through the Use of a Relaxation Algorithm'. Working Paper 9602, CEPREMAP, Paris.

- Myles G.D. [1995]. Public Economics. Cambridge University Press. 
- Nelissen J.H.M. [1995]. 'Lifetime Income Redistribution by the OldAge State Pension in The Netherlands', Journal of Public Economics, $58,429-451$.

- Pestieau P. [1999]. 'The Political Economy of Redistributive Social Security', IMF Working Paper 99/180.

- Rillaers A. [2000]. 'Unemployment Benefits and Basic Income. An Evaluation', IRES Working Paper 22, Université catholique de Louvain.

- Romer D. [1996]. Advanced Macroeconomics. Mc Graw Hill.

- Van der Linden B. [2002].'Is Basic Income a Cure for Unemployment in Unionized Economies? A General Equilibrium Analysis', Annales d'Economie et de Statistique, 66,81-105.

- Van der Linden B. [2004] 'Active citizen's income, unconditional income and participation under imperfect competition : A normative analysis', Oxford Economic Papers, 56, No. 1, pp. 98-117.

- Van Oorschot W. and Boos C. [1999]. 'Dutch Pension Policy and the Ageing of the Population', The European Journal of Social Security, $1(3), 295-311$.

- Van Parijs P. [2000]'Basic Income:Guaranteed Income for the 21st Century?', Fundaci Rafael Campalans.

- Vanderborght Y. [2002].'Basic Income in Belgium and the Netherlands: Implementation through the Back Door?', mimeo.

- World Bank [1994]. Averting the Old Age Crisis : Policies to Protect the Old and Promote Growth. World Bank, Washington. 


\section{Appendix A}

In this Appendix we prove a result used in Section 4.2: when $\gamma$ increases, the $B P$ and thus the income of the unskilled increase.

This is not trivial because $\gamma$ on one hand as a positive effect on $p$ and on the other hand has a negative impact on it since it reduces aggregate labor supply:

$$
\begin{gathered}
\frac{\partial p}{\partial \gamma}=\frac{\partial \gamma w_{1} e l_{1}}{\partial \gamma}=w_{1} e\left[l_{1}+\gamma \frac{\partial l_{1}}{\gamma}\right]= \\
=(1+\beta)\left\{\frac{[R(1-\tau)+\tau-\gamma(1-e)][R(1-\tau)+\tau-\gamma]-\gamma e[R(1-\tau)+\tau]}{[R(1-\tau)+\tau-\gamma(1-e)]^{2}}\right\}
\end{gathered}
$$

The numerator of this expression can be written as:

$$
\underbrace{[R(1-\tau)+\tau]}_{+} \underbrace{[R(1-\tau)+\tau-2 \gamma]}_{?}+\underbrace{\gamma^{2}(1-e)}_{+}
$$

which would be positive if:

$$
[R(1-\tau)+\tau-2 \gamma]>0
$$

Using equations (29) and (2) to obtain $R$, this inequality could be written as:

$$
\alpha(1+\beta)+(1-\alpha) \tau+(1-\alpha) \beta \tau-(1-\alpha) \beta \gamma-(1-\alpha) \beta \gamma>0
$$

that holds for sure since $\tau>\gamma$.

Thus we have shown that $\frac{\partial p}{\partial \gamma}>0$.

\section{Appendix B}

In this Appendix we prove a result used in Section 4.2: the derivative of the utility function of the skilled with respect to $\gamma$ is given by equation (55). 
From equation (14) we have that:

$$
\frac{\partial U_{1}}{\partial \gamma}=\frac{1}{c_{1}} \frac{\partial c_{1}}{\partial \gamma}+\beta \frac{1}{d_{1}} \frac{\partial d_{1}}{\partial \gamma}-\frac{\partial l_{1}}{\partial \gamma}
$$

$c_{1}$ and $d_{1}$ turns out to be the same as in equations (32) and (33), while $\frac{\partial l_{1}}{\partial \gamma}$ is given by equation (53) ; substituting into (60) we get equation (55). 